Int. J. Electrochem. Sci., 12 (2017) 9017 - 9039

International Journal of

ELECTROCHEMICAL

SCIENCE

www.electrochemsci.org

\title{
Depolymerized Oil Palm Frond (OPF) Lignin Products as Corrosion Inhibitors for Mild Steel in 1 M HCl
}

\author{
Affaizza Mohamad Shah, Afidah Abdul Rahim*, Mohamad Nasir Mohamad Ibrahim and \\ Mohd. Hazwan Hussin \\ Department of Physical Chemistry, School of Chemical Sciences, Universiti Sains Malaysia, 11800, \\ Pulau Pinang Malaysia \\ *E-mail: afidah@usm.my
}

doi: $10.20964 / 2017.10 .66$

Received: 10 January 2017 / Accepted: 11 August 2017 / Published: 12 September 2017

The inhibitory effects of depolymerized alkaline soda (OSL), kraft (OKL) and organosolv (OOL) lignin products via nitrobenzene oxidation method on mild steel corrosion in $1.0 \mathrm{M} \mathrm{HCl}$ medium were investigated by using weight loss measurement, potentiodynamic polarization, and electrochemical impedance spectroscopy (EIS) methods. The corrosion inhibition efficiency obtained from all methods was found to increase with increased concentrations for all depolymerized lignin products. Polarization measurements indicated that OSL, OKL, and OOL acted as mixed type inhibitors. Ferric reducing power activity of OSL, OKL, and OOL that has been determined via reducing power assay showed that all three inhibitors have the ability to act as antioxidants. The adsorption behavior of OSL, OKL, and OOL products was also studied; the experimental data have been found to well fit the Langmuir adsorption isotherm and the $\Delta G^{\circ}{ }_{a d s}$ values proved that physisorption dominated the adsorption process. High-performance liquid chromatography (HPLC) analysis was carried out to quantify the fractions of depolymerized lignin and seven phenolic constituents ( $p$-hydroxybenzoic acid, vanillic acid, syringic acid, $p$-hydroxybenzaldehyde, vanillin, syringaldehyde, and $p$-hydroxyacetophenone) were found to be present in OSL, OKL, and OOL; out of which, three (syringaldehyde, vanillin, and $p$ hydroxybenzaldehyde) were identified as the main compounds responsible for corrosion inhibition of mild steel in $1 \mathrm{M} \mathrm{HCl}$ medium. The analysis revealed that only phenolic aldehydes (S, V and 4-HB) gave significant contributions to the corrosion inhibition for mild steel in $1 \mathrm{M} \mathrm{HCl}$ that do not depend on the total initial concentration of $\mathrm{S}, \mathrm{V}$ and 4-HB in the depolymerized lignin products. The results from the HPLC analysis corroborates well with the electrochemical and weight-loss measurements results. The surface morphology of mild steel was monitored by scanning electron microscopy (SEM). It was observed that the roughness of the surface was reduced with the addition of an inhibitor as compared to the one without an inhibitor indicating reduced corrosion rate of mild steel that is supported by the X-ray diffraction (XRD) analysis.

Keywords: Lignin, corrosion inhibitor, electrochemical, mild steel corrosion, HPLC 


\section{FULL TEXT}

(C) 2017 The Authors. Published by ESG (www.electrochemsci.org). This article is an open access article distributed under the terms and conditions of the Creative Commons Attribution license (http://creativecommons.org/licenses/by/4.0/). 